\title{
Murine Typhus in Canary Islands, Spain, 1999-2015
}

\author{
José María Robaina-Bordón, Cristina Carranza-Rodríguez, Michele Hernández-Cabrera, \\ Margarita Bolaños-Rivero, Elena Pisos-Álamo, Nieves Jaén-Sánchez, \\ Araceli Hernández-Betancor, Laura Suárez-Hormiga, José Luis Pérez-Arellano
}

To document the epidemiology, clinical features, and outcomes of murine typhus patients in the Canary Islands (Spain), we analyzed data that were retrospectively collected for 16 years for 221 patients. Murine typhus in the Canary Islands is characterized by a high rate of complications (31.6\%), mainly liver, lung, kidney or central nervous system involvement.

$\mathrm{M}$ urine typhus is a febrile disease caused by Rickettsia typhi (1). Rickettsia are obligate, intracellular, gram-negative bacilli that are transmitted to mammals by various arthropod vectors, including ticks, lice, mites, and fleas (2). The classic $R$. typhi life cycle involves rats of the subgenus Rattus (such as $R$. rattus and R. norvegicus) and their fleas (especially Xenopsylla cheopis). Adaptation to new reservoirs (cats, dogs, opossums) and vectors, in particular Ctenocephalides felis (cat flea), has probably led to the reappearance of murine typhus in industrialized countries (3).

Murine typhus remains a neglected disease despite its worldwide distribution. It is one of the most frequent causes of fever of intermediate duration (FID), defined as fever of 7-28 days, and is not associated with localizing signs or diagnostic clues after a complete evaluation in southern Spain and the Canary Islands $(4,5)$. Underdiagnosis represents a major health cost because unnecessary diagnostic tests might be performed and treatment might be

Author affiliations: Universidad de Las Palmas de Gran Canaria, Las Palmas de Gran Canaria, Spain (J.M. Robaina-Bordón,

C. Carranza-Rodríguez, M. Hernández-Cabrera, E. Pisos-Álamo,

N. Jaén-Sánchez, L. Suárez-Hormiga, J.L. Pérez-Arellano);

Hospital Universitario de Gran Canaria Doctor Negrín, Las Palmas

de Gran Canaria (J.M. Robaina-Bordón); Complejo Hospital-

ario Universitario Insular-Materno Infantil de Gran Canaria, Las

Palmas de Gran Canaria (C. Carranza-Rodríguez, M. Hernández-

Cabrera, M. Bolaños-Rivero, E. Pisos-Álamo, N. Jaén-Sánchez,

A. Hernández-Betancor, L. Suárez-Hormiga, J.L. Pérez-Arellano)

DOI: https://doi.org/10.3201/eid2702.191695 inadequate (6). Although it is considered a mild disease, a large number of patients require hospital admission and show development of life-threatening complications (7). Our aim was to document the epidemiology, clinical features, and outcome of murine typhus in the Canary Islands (Spain).

\section{The Study}

The study included 221 adults $>14$ years of age who were inpatients and outpatients at the Hospital Universitario Insular of Las Palmas (Las Palmas de Gran Canaria, Spain), who received a diagnosis of murine typhus during June 1, 1999-December 31, 2015. Epidemiologic, clinical, and laboratory data were retrospectively collected from medical records. Diagnosis of murine typhus was based on detection of antibodies against $R$. typhi by using an indirect immunofluorescence test and 2 criteria. Criterion 1 was titer $\geq 1: 1,280$ for IgM in 1 sample, and criterion 2 was a 4 -fold increase in IgG titers between 2 consecutive samples. A total of $72(32.6 \%)$ patients were given a diagnosis according to criterion 1, and 149 (67.4\%) patients were given a diagnosis according to criterion 2. Clinical and laboratory data for both groups were analyzed separately.

Murine typhus was more frequent during JulyNovember (Figure 1). The mean \pm SD number of cases diagnosed per year was $18 \pm 5.33$. We provide the annual distribution of cases (Figure 2). Most $(91.4 \%, 202 / 221)$ case-patients lived in urban areas; $73.3 \%(162 / 221)$ were male; and the median age was 40 years (interquartile range 28.5-52.5 years). Most $(88.7 \%, 188 / 212)$ reported close contact with animals, especially dogs $(66 \%, 140 / 212)$ and cattle $(42 \%$, $89 / 212)$. Arthropod bites were reported by 34 (19.5\%) of 174 case-patients.

We provide the main clinical features recorded (Table 1). A total of $180(82.95 \%)$ of 217 patients had high fever (median temperature $39.8^{\circ} \mathrm{C}$ ) of $>1$ week duration. Pharyngitis was more frequently observed 


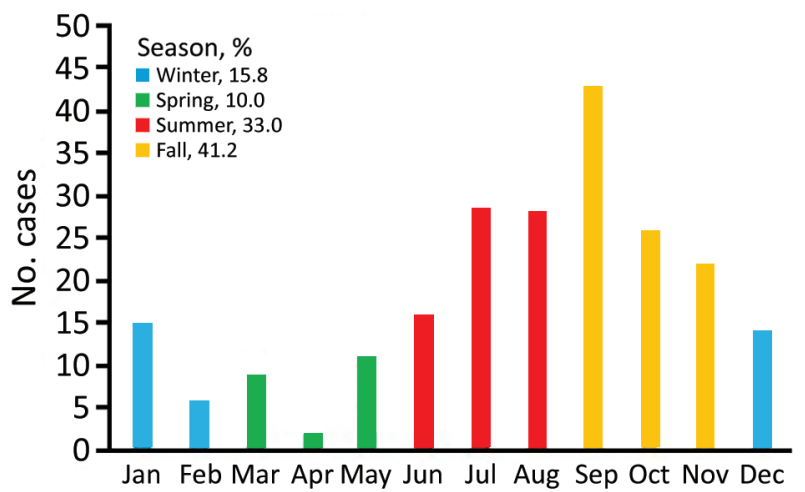

Figure 1. Monthly distribution of cases of endemic murine typhus, Canary Islands, Spain, 1999-2015.

for younger $(<20$ years of age) patients $(7 / 20,35 \%)$ than for older patients $(12 / 169,7.1 \%)(p=0.001)$. Rash was present more often in younger patients $(8 / 19,42.1 \%)$ than in older patients $(42 / 190,22.1 \%)$ $(\mathrm{p}=0.05)$. We also provide laboratory findings (Table 2). Most $(184 / 195,94.4 \%)$ had urinalysis alterations in the form of microhematuria, proteinuria, or leukocyturia.

Complications developed in $31.6 \%(68 / 215)$ of patients, especially hepatitis $(22 / 221,10.0 \%)$, acute renal failure $(21 / 215,9.8 \%)$, meningitis (12/215, $5.6 \%)$, and pneumonia $(9 / 215,4.2 \%)$. No differences were found between patients given a diagnosis by using criterion 1 or 2 (Appendix, https://wwwnc. cdc.gov/EID/article/27/2/19-1695-App1.pdf).

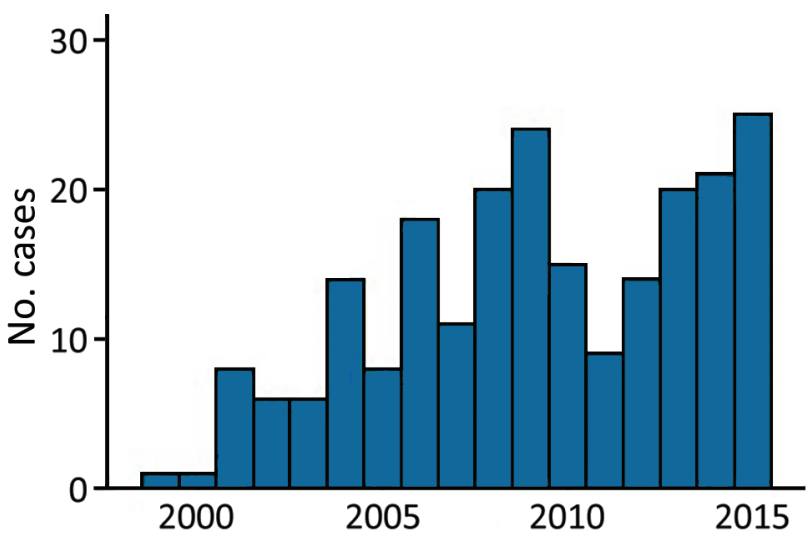

Figure 2. Annual distribution of cases of murine typhus, Canary Islands, Spain, 1999-2015.

Cerebrospinal fluid samples from patients who had meningitis were characterized by a clear appearance, moderate mononuclear pleocytosis (range 6-43 cells), mild proteinorachia, and standard glucose levels. Round pneumonia developed in 2 patients and retinitis in 1 patient.

A total of $51(22.6 \%)$ of the 221 patients were hospitalized: 29 (56.9\%) had complications, $12(23.5 \%)$ experienced vomiting, and $10(19.6 \%)$ needed a diagnostic workup. The average length of hospital stay was short (median 6 days; interquartile range 4-9 days). Seven patients did not receive treatment because of spontaneous recovery. The remaining patients received doxycycline. Two patients required admission

\begin{tabular}{|c|c|c|c|c|}
\hline Finding & Total, no. (\%) & $\begin{array}{c}\lg M \geq 1: 1,280, \\
\text { no. }(\%)^{*}\end{array}$ & $\begin{array}{c}\text { 4-fold IgG titer increase, } \\
\text { no. (\%)† }\end{array}$ & $\mathrm{p}$-value \\
\hline \multicolumn{5}{|l|}{ Symptom or sign } \\
\hline Headache, $n=206$ & $181(87.9)$ & $59(88.1)$ & $122(87.8)$ & 0.95 \\
\hline Sweating, $n=175$ & $129(73.7)$ & $44(74.6)$ & $85(73.3)$ & 0.85 \\
\hline Myalgias, $n=186$ & $135(72.6)$ & $39(65)$ & $96(76.2)$ & 0.11 \\
\hline Nausea/vomiting, $n=206$ & $103(50)$ & $32(47.8)$ & $71(51.1)$ & 0.66 \\
\hline Dry cough, $n=200$ & $79(39.5)$ & $23(36.5)$ & $56(40.9)$ & 0.56 \\
\hline Rash, $n=211$ & $56(26.5)$ & $14(21.2)$ & $36(25.2)$ & 0.53 \\
\hline Abdominal pain, $\mathrm{n}=200$ & $45(22.5)$ & $15(22.7)$ & $30(22.4)$ & 0.96 \\
\hline Classic triad, $n=201 \ddagger$ & $46(22.9)$ & $14(21.5)$ & $32(23.5)$ & 0.75 \\
\hline Conjunctivitis, $n=201$ & $41(20.4)$ & $12(18.8)$ & $29(21.2)$ & 0.69 \\
\hline Diarrhea, $n=221$ & $41(18.6)$ & $11(15.3)$ & $30(20.1)$ & 0.38 \\
\hline Odynophagia, $n=182$ & $24(13.2)$ & $16(13.1)$ & $8(13.3)^{\prime}$ & 0.97 \\
\hline Tachycardia, $n=164$ & $75(45.7)$ & $28(54.9)$ & $47(41.6)$ & 0.11 \\
\hline Hepatomegaly, $n=209$ & $37(17.7)$ & $12(17.9)$ & $25(17.6)$ & 0.96 \\
\hline Relative bradycardia, $n=162 \S$ & $21(13)$ & $3(5.9)$ & $18(16.2)$ & 0.07 \\
\hline Pharyngitis, $n=189$ & $19(10.1)$ & $8(12.7)$ & $11(8.7)$ & 0.39 \\
\hline Lymphadenopathy, $n=198$ & $16(8.1)$ & $10(15.6)$ & $6(4.5)$ & 0.01 \\
\hline Splenomegaly, $\mathrm{n}=209$ & $17(8.1)$ & $5(7.5)$ & $12(8.5)$ & 0.81 \\
\hline Altered pulmonary auscultation, $n=210$ & $17(8.1)$ & $7(10.3)$ & $10(7)$ & 0.42 \\
\hline Flea bite, $n=93$ & $6(6.5)$ & $0(0)$ & $6(9.4)$ & 0.17 \\
\hline Costovertebral angle tenderness, $n=199$ & $11(5.5)$ & $6(9.2)$ & $5(3.7)$ & 0.18 \\
\hline Jaundice, $n=210$ & $11(5.2)$ & $4(5.9)$ & $7(4.9)$ & 0.75 \\
\hline
\end{tabular}

*Patients given a diagnosis by testing of 1 sample (criterion 1).

†Patients given a diagnosis by testing of 2 consecutive samples (criterion 2).

†Fever, headache and rash.

$\S$ Temperature $\geq 38.9^{\circ} \mathrm{C}$ and heart rate $\leq 110$ beats $/ \mathrm{min}$ in the absence of treatment with $\beta$-blockers. 
Table 2. Laboratory test results for patients with cases of endemic murine typhus, Canary Islands, Spain, 1999-2015*

\begin{tabular}{|c|c|c|c|c|c|}
\hline Finding & No. $(\%)$ & $\begin{array}{c}\lg M \geq 1: 1,280 \\
\text { no. }(\%) \dagger\end{array}$ & $\begin{array}{c}\text { 4-fold lgG titer } \\
\text { increase, no. (\%) } \neq\end{array}$ & $\mathrm{p}$-value & Cutoff values \\
\hline Anemia, $\mathrm{n}=220$ & $38(17.3)$ & $16(22.5)$ & $22(14.8)$ & 0.15 & $\begin{array}{c}<12 \mathrm{~g} / \mathrm{dL} \mathrm{Hb} \text { in women, }<13 \mathrm{~g} / \mathrm{dL} \\
\mathrm{Hb} \text { in men }\end{array}$ \\
\hline Leukopenia, $n=220$ & $23(10.5)$ & $7(9.9)$ & $16(10.7)$ & 0.26 & $<4,000 / \mu \mathrm{L}$ \\
\hline Leukocytosis, $n=220$ & $42(19.1)$ & $18(25.4)$ & $24(16.1)$ & 0.26 & $>11,000 / \mu \mathrm{L}$ \\
\hline Thrombocytopenia, $\mathrm{n}=218$ & $127(58.3)$ & $28(39.4)$ & $99(67.3)$ & $<0.01$ & $<150,000 / \mu \mathrm{L}$ \\
\hline Increased ESR, $n=106$ & $64(60.4)$ & $27(65.9)$ & 37 (56.9) & 0.42 & $\begin{array}{l}\text { Upper limit of normality calculated } \\
\text { according to age and sex }\end{array}$ \\
\hline Prolonged PT, $\mathrm{n}=197$ & $82(41.6)$ & 27 (42.9) & $55(41)$ & 0.81 & $<80 \%$ \\
\hline Increased aPTTr, n = 188 & $6(3.2)$ & $2(3.4)$ & $4(3.1)$ & 0.99 & $>1.2$ \\
\hline Plasma Cr increase, $n=215$ & $47(21.9)$ & $16(23.5)$ & $31(21.1)$ & 0.72 & $>1.2 \mathrm{mg} / \mathrm{dL}$ \\
\hline Hyponatremia, $n=205$ & $119(58)$ & $30(50)$ & $89(61.4)$ & 0.13 & $<135 \mathrm{mEq} / \mathrm{L}$ \\
\hline Plasma CK increase, $n=97$ & $20(20.6)$ & $5(13.5)$ & $15(25)$ & 0.17 & $>232 \mathrm{U} / \mathrm{L}$ \\
\hline Plasma urea increase, $n=211$ & 36( & $12(18.5)$ & $24(16.4)$ & 0.72 & $>40 \mathrm{mg} / \mathrm{dL}$ \\
\hline Plasma LDH increase & $131(94.9)$ & $40(90.9)$ & $91(96.8)$ & 0.21 & $>190 \mathrm{U} / \mathrm{L}$ \\
\hline Plasma ALT increase, & $184(93.4)$ & 59 (92.2) & $125(94)$ & 0.76 & $>35 \mathrm{U} / \mathrm{L}$ \\
\hline Plasma AST increase, $n=196$ & $182(92.9)$ & $55(88.7)$ & $127(94.81)$ & 0.14 & $>35 \mathrm{U} / \mathrm{L}$ \\
\hline Plasma AP increase, $n=109$ & $38(34.9)$ & $10(25.6)$ & $28(40)$ & 0.15 & $>136 \mathrm{U} / \mathrm{L}$ \\
\hline Plasma GGT increase, $n=166$ & $91(54.8)$ & $29(52.7)$ & $62(55.9)$ & 0.74 & $>85 \mathrm{U} / \mathrm{L}$ \\
\hline Microhematuria, $\mathrm{n}=195$ & $146(74.9)$ & $45(72.6)$ & $101(75.9)$ & 0.6 & $>5 \mathrm{RBCs} / \mathrm{mm}^{3}$ \\
\hline Proteinuria, $n=195$ & $169(86.7)$ & $54(87.1)$ & $115(86.5)$ & 0.9 & Positive urine test strip \\
\hline Leukocyturia, $n=194$ & $123(63.4)$ & $38(62.3)$ & $85(63.9)$ & 0.83 & $>10$ WBCs $/ \mathrm{mm}^{3}$ \\
\hline \multicolumn{6}{|c|}{$\begin{array}{l}\text { *ALT, alanine aminotransferase; AP, alkaline phosphatase; aPTTr, activated partial thromboplastin time ratio; AST, aspartate aminotransferase; Cr, } \\
\text { creatinine; CK, creatine kinase; ESR, erythrocyte sedimentation rate; GGT, } \gamma \text {-glutamyl transpeptidase; Hb, hemoglobin; LDH, lactate dehydrogenase; PT, } \\
\text { prothrombin Time; RBCs, red blood cells; WBCs, white blood cells. } \\
\text { †Patients given a diagnosis by testing of } 1 \text { sample (criterion 1). } \\
\text { łPatients given a diagnosis by testing of } 2 \text { consecutive samples (criterion 2). }\end{array}$} \\
\hline
\end{tabular}

to the intensive care unit because of multiple organ failure, and no patients died. Low transient IgM titers and no IgG titers against other microorganisms were found in admission serum samples, especially against Coxiella burnetii $(36 / 218,16.5 \%)$ and Epstein-Barr virus $(13 / 218,6.0 \%)$.

\section{Conclusions}

Murine typhus was diagnosed primarily in middleage men and showed a similar male:female ratio as in other clinical series (8). The seasonal prevalence of murine typhus during late summer and fall has been described (7). This temporal pattern seems to be related to the increased propagation activity of the vector linked to higher temperatures. The number of annual cases is similar to that reported by others (9-11), and diagnoses increased over the study period. However, these data probably underestimate the incidence of murine typhus because of the absence of clinical hallmarks and the fact that this disease is self-limiting.

The clinical features of murine typhus observed in this study are consistent with those reported by Tsioutis et al. (7); high fever and intense headaches were the most common clinical features. Most of the patients fulfilled the criterion for FID. There were differences by age groups. The presence of a rash was rare among elderly patients, as reported $(12,13)$. This finding makes the diagnostic utility of the classic triad of fever, headache, and rash somewhat debatable, especially for older patients. Furthermore, patients $<20$ years of age sometimes showed a clinical profile indistinguishable from that for infectious mononucleosis associated with pharyngitis, visceromegaly, lymphadenopathy, and atypical lymphocytosis.

The most common finding for blood counts was thrombocytopenia $(127 / 218,58.3 \%)$. A prolonged prothrombin time was common. No association was observed between a prolonged prothrombin time and complications, which is in contrast to the results of Chang et al. (14). Hypertransaminasemia was the most common serum alteration, which reached values typical for viral, toxic, or ischemic hepatitis in $10 \%$ of case-patients. However, clinical hepatitis, with the presence of hepatomegaly and increased levels of bilirubin, was much less frequent.

The higher incidence of renal damage for patients with murine typhus in the Canary Islands has been reported (15). This differential finding could be caused by specific strains of $R$. typhi that have a particular tropism, although there is no solid evidence to confirm this possibility.

Transient IgM titers against other microorganisms in admission serum samples are common. Obtaining 2 independent samples during an interval of 2 weeks is essential to avoid false-negative results or misdiagnoses.

A limitation of this study is its retrospective design, although based on an established protocol. Another 
limitation is the possibility of cross-reactivity; crossreactivity is common in rickettsial diseases, and some cases diagnosed as murine typhus may have been caused by other rickettsial species. A third limitation is use of a single serum sample as a diagnostic criterion, which although used in most clinical case series is not rigorous, and previous exposure to pathogens as the cause of seroreactivity cannot be completely ruled out. However, the relatively high IgM cutoff point and the absence of relevant differences between patients given a diagnosis by using 1 sample and those with confirmed seroconversion support the data presented.

Murine typhus is a major cause of FID in the Canary Islands. Complications are frequent, especially in the elderly, usually with renal, hepatic, respiratory, or central nervous system involvement. These results should help raise awareness among physicians about the need to identify cases earlier, start treatment promptly, and thus improve clinical outcomes.

\section{Acknowledgment}

We thank Janet Dawson for her help in revising the English version of the manuscript.

\section{About the Author}

Dr. Robaina-Bordón is an internal medicine resident at the University Hospital of Gran Canaria Dr. Negrín, Las Palmas de Gran Canaria, Spain. His primary research interests are native and imported rickettsioses and fever of intermediate duration.

\section{References}

1. Bolaños M, Angel-Moreno A, Pérez-Arellano JL. Murine typhus. A disease to think about here and now [in Spanish]. Med Clin (Barc). 2004;122:383-9.

2. Blanton LS. The rickettsioses, a practical update. Infect Dis Clin North Am. 2019;33:213-29. https:// doi.org/10.1016/ j.idc.2018.10.010

3. Gillespie JJ, Ammerman NC, Beier-Sexton M, Sobral BS, Azad AF. Louse- and flea-borne rickettsioses: biological and genomic analyses. Vet Res. 2009;40:12. https://doi.org/ 10.1051/vetres:2008050

4. Bernabeu-Wittel M, Pachón J, Alarcón A, López-Cortés LF, Viciana P, Jiménez-Mejías ME, et al. Murine typhus as a common cause of fever of intermediate duration: a 17-year study in the south of Spain. Arch Intern Med. 1999;159:872-6. https://doi.org/10.1001/archinte.159.8.872
5. Parra Ruiz J, Peña Monje A, Tomás Jiménez C, Parejo Sánchez MI, Vinuesa García D, Muñoz Medina L, et al. Clinical spectrum of fever of intermediate duration in the south of Spain. Eur J Clin Microbiol Infect Dis. 2008;27:993-5. https://doi.org/10.1007/s10096-008-0530-6

6. Vohra RF, Walker DH, Blanton LS. Analysis of health-care charges in murine typhus: need for improved clinical recognition and diagnostics for acute disease. Am J Trop Med Hyg. 2018;98:1594-8. https:// doi.org/10.4269/ ajtmh.17-0411

7. Tsioutis C, Zafeiri M, Avramopoulos A, Prousali E, Miligkos M, Karageorgos SA. Clinical and laboratory characteristics, epidemiology, and outcomes of murine typhus: a systematic review. Acta Trop. 2017;166:16-24. https://doi.org/10.1016/j.actatropica.2016.10.018

8. Miguélez M, Laynez P, Linares M, Hayek M, Abella L, Marañez I. Murine typhus in Tenerife. Clinicoepidemiological study and differential clinical features with $Q$ fever [in Spanish]. Med Clin (Barc). 2003;121:613-5.

9. Psaroulaki A, Christou C, Chochlakis D, Tsiligianni I, Sandalakis V, Georgalis L, et al. Murine typhus in Cyprus: a 9-year survey. Trans R Soc Trop Med Hyg. 2012;106:489-95. https://doi.org/10.1016/j.trstmh.2012.02.010

10. Chaliotis G, Kritsotakis EI, Psaroulaki A, Tselentis Y, Gikas A. Murine typhus in central Greece: epidemiological, clinical, laboratory, and therapeutic-response features of 90 cases. Int J Infect Dis. 2012;16:e591-6. https:/ / doi.org/ 10.1016/j.ijid.2012.03.010

11. Espinosa N, Cañas E, Bernabeu-Wittel M, Martín A, Viciana P, Pachón J. The changing etiology of fever of intermediate duration. Enferm Infecc Microbiol Clin. 2010;28:416-20. https:/ / doi.org/10.1016/j.eimc.2009.07.014

12. Tsioutis C, Chaliotis G, Kokkini S, Doukakis S, Tselentis Y, Psaroulaki A, et al. Murine typhus in elderly patients: a prospective study of 49 patients. Scand J Infect Dis. 2014; 46:779-82. https://doi.org/10.3109/00365548.2014.943283

13. Murray KO, Evert N, Mayes B, Fonken E, Erickson T, Garcia MN, et al. Typhus group rickettsiosis, Texas, USA, 2003-2013. Emerg Infect Dis. 2017;23:645-8. https:/ / doi.org/ 10.3201/eid2304.160958

14. Chang K, Lee NY, Ko WC, Lin WR, Chen YH, Tsai JJ, et al. Characteristics of scrub typhus, murine typhus, and $Q$ fever among elderly patients: prolonged prothrombin time as a predictor for severity. J Microbiol Immunol Infect. 2019;52:54-61. https://doi.org/10.1016/j.jmii.2016.08.023

15. Hernández Cabrera M, Angel-Moreno A, Santana E, Bolaños M, Francès A, Martín-Sánchez MS, et al. Murine typhus with renal involvement in Canary Islands, Spain. Emerg Infect Dis. 2004;10:740-3. https:/ / doi.org/10.3201/ eid1004.030532

Address for correspondence: José Luis Pérez-Arellano, Departamento de Ciencias Médicas y Quirúrgicas, Universidad de Las Palmas de Gran Canaria, 35080, Canary Islands, Spain; email: luis.perez@ulpgc.es 